Revista Iberoamericana, Vol. LXIX, Núm. 202, Enero-Marzo 2003, 215-227

\title{
RUPTURAS Y REPOSICIONAMIENTOS: LA INNOVACIÓN ESTÉTICA DE RODRIGO FRESÁN
}

\author{
POR \\ Silvia G. KuRlat Ares \\ George Mason University
}

\begin{abstract}
Al hablar de los cambios producidos en la literatura argentina de los últimos veinte años, a menudo se hace referencia al surgimiento de grupos o de escritores a quienes se identifica como vanguardistas: a falta de mejores definiciones, se ha señalado la emergencia de una "literatura de lo nuevo" o de una "escritura de los jóvenes". Los autores que integran esas listas no siempre son tan jóvenes como la crítica quiere creer y sus agendas de trabajo son, por cierto, difusas. Sin embargo, puede afirmarse que al terminar la dictadura a mediados de los ochenta aparecen textos que, claramente, intentan una ruptura con los modelos culturales e ideológicos que fueron hegemónicos hasta los años setenta. Los textos presentan algunos rasgos comunes que han permitido lecturas de conjunto a partir de los parámetros teóricos de la posmodernidad. Según la crítica, la "nueva literatura" intenta renunciar a un cierto realismo que amalgama literatura, política, ideología e historia. Entre otras características pueden mencionarse el astillamiento del sujeto y de la percepción de la experiencia, la pérdida de un centro teleológico, una crítica a la Historia nacional y también, el abandono de la literatura de compromiso. Además, este registro escriturario parece inscribir una reacción estética en contra de ciertas lecturas institucionalizadas (sobre todo dentro de la Academia de los EE.UU.) acerca de "lo latinoamericano”, cristalizadas en las vertientes sesentistas de realismo mágico. Debe notarse, sin embargo, que en el caso particular de la literatura argentina, esta reacción no es exclusiva de la llamada "literatura joven". En tanto que se debaten los temas en vigor en el campo cultural, es posible encontrar revisiones y lecturas críticas en esta vena en escritores tan distintos como Ernesto Schóo, David Viñas o Juan Carlos Martini Real, aunque esas reflexiones no intenten un quiebre discursivo y/o estético. A mediados de los ochenta, la presencia de textos que escriben abiertamente a contrapelo de los temas vigentes desde el centro mismo de la producción del campo, vuelve evidentes los primeros síntomas de una transformación en la semántica narrativa.

Con todo, en la mayoría de los casos, los intentos programáticos de renuncia a los parámetros realistas que han propuesto las diversas autodenominadas vanguardias han fracasado estrepitosamente. ${ }^{1}$ Posiblemente, la causa fundamental sea que muchos de estos
\end{abstract}

\footnotetext{
1 Nos referimos, en especial, a lo que atañe a la literatura como programa de las políticas de la hegemonía de izquierda de las décadas de los sesenta y setenta, cuando esas problemáticas se
} 
textos han instalado su(s) discurso(s) dentro del espacio narrativo que articula esas mismas problemáticas, es decir, el espacio donde literatura e Historia se cruzan para inscribirse en la siempre dudosa lógica de los mitos: reconstruir la Historia del siglo xIx es una obsesión de la literatura argentina. Con algunas excepciones puntuales, este es el caso de escritores “jóvenes” como Martín Caparrós, Carlos Eduardo Feiling, Alberto Laiseca o César Aira, a quienes la crítica ha agrupado con frecuencia bajo los rótulos que mencionábamos más arriba.

En este marco, resulta de especial interés la aparición de algunos cuentos de Fogwill, de las novelas de Marcelo Cohen (sobre todo El país de la dama eléctrica), de Matilde Sánchez, de Juan Forn y, finalmente, de las novelas/cuentos de Rodrigo Fresán, de las cuales nos ocuparemos en este trabajo. Debemos subrayar que estos escritores no tienen una intención programática unificada ni constituyen en modo alguno un grupo homogéneo. Siendo narrativas extraordinariamente dispares, conforman un espacio de renovación que se aleja no sólo de las prácticas, sino también de los cuestionamientos y búsquedas centrales en la literatura argentina hasta mediados de los ochenta. Las novelas tienen un cierto "aire de familia” (y esto dicho con toda ironía) y por ello, son emblemáticas del tipo de cambios que parecen señalar el surgimiento de nuevas tendencias literarias. Sus narraciones parecen ser las emergentes de lo que vendrá, en el sentido de que condensan tanto las claves de un aparato simbólico vinculado a una estética joven que no quiere serlo, ${ }^{2}$ como un lenguaje donde la memoria histórica aparece excluida (o, de estar presente, hay una buena distancia crítica), creando lo que Jameson ha llamado “a new kind of flatness”.

En términos generales, puede decirse que estos textos constituyen sus estéticas sobre una doble operación. Por un lado, y como ya se ha señalado, ${ }^{3}$ estas son narrativas estrictamente urbanas, que incorporan como parte de su discurso las poéticas del rock local, las narrativas sobre nuevas tecnologías, la lógica del mercado como parte constitutiva de la producción cultural, la reconstitución de las clases medias, los nuevos tipos de movilidad social, etc. En esa operación, los textos actúan en abierto enfrentamiento con lo que podría identificarse como una genealogía temática central para la producción del campo cultural argentino: abandonan estos materiales, abriendo su sistema de producción

articularon con especial intensidad. Esas temáticas pueden definirse como la reconstrucción del discurso histórico en función de dar voz a los derrotados de la Historia nacional, la constitución del Estado-Nación durante el siglo xix y las relaciones de los intelectuales con ese proceso histórico. Para mayores detalles, puede consultarse mi tesis de doctorado.

${ }^{2}$ En este sentido, esta escritura joven, más bien, recupera una operación estética ya presente en los sectores menos transitados del campo cultural y, en lugar de reciclar el canon, re-escribe su sintaxis. Tomamos la idea de las observaciones de Beatriz Sarlo sobre la naturaleza del "uniforme” de las diversas tribus juveniles. Dice: "no la diferencia, el significado de los elementos que combina, sino la sintaxis con que se articulan. Pura forma, su disfraz se distingue de la forma de la moda 'legítima' porque no aspira a la universalidad sino a una fracción particular: marca su edad, su condición juvenil, y no su condición social ni su dinero. Con el disfraz, la chica cumple por completo el ciclo de algo que ya comenzaba a esbozarse en los cincuenta: el 'estilo joven'. La juventud no es una edad sino una estética de la vida cotidiana" (38; el subrayado es mío)

${ }^{3}$ Véase Palaversich, Plotnik y Benzecry. El último trabajo es de especial interés para comprender el entramado entre agentes culturales de esferas diversas en su relación con la producción cultural y el mercado. 
a zonas discursivas relacionadas con el consumo, el mercado, los medios masivos de comunicación y la música popular. ${ }^{4}$ Sin ser novelas marginales, logran centralizar operaciones que, hasta mediados de los ochenta, sólo eran posibles en los llamados géneros menores. ${ }^{5}$

En estos textos, aparece un tipo de sujeto que establece una relación de ajenidad con el mundo que lo rodea. En la mayoría de los casos tal operación es posible porque esa ajenidad es consecuencia de una renuncia a los mandatos de la Historia. Se crea un sujeto que vive su astillamiento como un proceso de alienación necesario para conservar la identidad (en lo privado) y la ética y la cordura (en lo social). La operación es curiosa porque, como respuesta a ese mismo proceso de desintegración, una buena parte de la poética del rock nacional (por tomar un ejemplo) apela a la inversión de la fórmula sarmientina, convirtiendo el campo bárbaro en un espacio utópico (especialmente en las letras de fusión musical que se entroncan con el folclore). Por otro lado, el discurso narrativo se presenta dentro de la lógica mayor de las relaciones entre literatura e Historia, pero desde una perspectiva que renuncia a toda posibilidad de escribir mitos o utopías de clase alguna y que, sin ser celebratorias, instauran lo que podríamos llamar un vacío productivo. Se escribe ex-nihilo. Esa carencia clausura los mitos de la Historia nacional en un espacio de pasado absoluto que permite a los personajes leer la Historia como acontecimientos individualizados (por decirlo de algún modo), dejando el devenir de la Historia (de la Gran Historia) fuera del espacio literario. Lo que se desvanece en el discurso narrativo de las novelas que nos interesan aquí es la impronta del siglo xix. Por decirlo de algún modo, es como si el fantasma de Sarmiento finalmente hubiese sido exorcizado.

Teniendo en cuenta el presente marco de referencias, este trabajo analiza en qué medida novelas como las de Rodrigo Fresán (1963) trazan los soportes de una renovación estética dentro del campo cultural argentino y en qué forma la incorporación de nuevos materiales apuntala la aparición de temáticas que rompen con aquellos elementos que conformaron su hegemonía. Tomando como ejemplos los textos Vidas de santos (1993) y Esperanto (1995/7), se trazará el arco de estas operaciones desde el momento de su primera emergencia dentro del campo cultural hasta que toman forma y solidez, articulando un discurso reconocible y relativamente cohesivo.

Vidas de santos es el segundo texto de Fresán. Construida de la misma forma que su primer libro (Historia argentina, 1991), la narración se presenta como una serie de cuentos cuyo entramado teje el soporte de una novela (en algo que recuerda un poco la novela que

\footnotetext{
${ }^{4}$ No es de ningún modo la operación que hace Manuel Puig con la cultura de masas en sus textos, aunque podría (de hacerse un rastreo diacrónico de esas operaciones en el campo) señalárselo como un antecedente. Con todo, y aunque en Puig hay un fuerte efecto crítico, sus operaciones no son suficientes como para atacar y desbancar los temas en vigor dentro del campo cultural. En cierta medida, sus novelas celebran la existencia misma de tales temas. En los textos de que nos ocupamos aquí, por el contrario, sin que haya un ataque frontal al statu quo literario o sin que se programe una renovación estética (que acaba por ser la consecuencia más evidente), lo que más bien puede leerse es una extrema desconfianza hacia la capacidad de producción de los temas vigentes.

${ }^{5}$ Cuando hablamos de géneros menores nos referimos, sobre todo, a la novela erótica y la ciencia ficción, donde las operaciones de lectura crítica de los materiales presentes en el campo cultural son más exitosas. He estudiado la forma en que se realizan estas operaciones en otros trabajos.
} 
buscaba Rodolfo Walsh allá por los setenta). Sin aparecer como una innovación clara en el sentido que le hubiera dado la narrativa de las décadas anteriores, la ausencia de una estructura de genre articula una primera negación: la de la imposibilidad de separar las actividades de escritura de las de lectura e interpretación. En este sentido, Vidas de santos reflexiona sobre la naturaleza de la relación, mediatizada o no, entre lenguaje ficcional e histórico. Lo que constituye el texto es la relación de la escritura y la lectura de los cuentosnovela, por una parte, y de la realidad y su interpretación, por otra. Ambos planos aparecen cruzados como parte de un mismo continuum cuya estabilidad se resquebraja por su mutua interferencia, por la presencia constante de múltiples lecturas y por las distintas voces (de los sujetos fragmentados que son sus portadores) que finalmente terminan destrozando el nivel de la fábula, obligando a las narraciones a desaparecer como tales, para ser sólo las posibles versiones de los posibles relatos en los que se disipan los textos. En los cuentos, todo tiende a disgregarse en minúsculas partículas en donde se hace imposible distinguir sujetos, objetos y relatos.

Esta operación es de especial relevancia para textos que tienen que inscribirse en un campo cultural que funciona en torno a las infinitas re-escrituras de un gran texto histórico nacional. Si en efecto, en palabras de Piglia, existe una relación causa-efecto entre novela y Estado, la voz que constituye ese doble discurso es la primera que se pone en la mira del texto. La novela sólo puede operar sobre la negación de toda posible figura de autoridad, textual, intelectual o política: de otro modo, se vería reducida a "producir Estado" a través de su propio discurso. Para probar este punto, el graffiti "Dio non esiste, ma è un grande personaggio" (9) se impone como declaración inicial de principios. Si algo tienen en común las múltiples formas de deidad es que otorgan cierto orden y consistencia al mundo. Lo divino establece formas de comprensión e interpretación a través de una entidad nuclear. Aceptar la muerte de Dios tal y como fue planteada por Nietzsche en el siglo xix, aunque elimine la noción de absoluto, no elimina su necesidad: de ahí que los textos batallen entre lanzarse a la búsqueda de tales figuras o eliminarlas. Dios, como personaje, intentaría cubrir un hiato, en un movimiento ambivalente que no acaba de definirse, sólo para concluir en el fracaso que se inscribe en la ambigüedad de la misma escritura. Porque Dios, como personaje, es sólo una de las muchas voces que intentan abrirse paso en el texto, a pesar de ser, con todo, la única voz ausente. Y es que si Dios no existe en el nivel de lo real, tampoco puede ser un personaje en el nivel de la ficción. El texto de Vidas de santos acaba implotando porque la ausencia de estructura textual es, justamente, la presencia/ausencia de Dios, es decir la traición del narrador que decide velar su voz, dejando el texto librado al azar de las múltiples lecturas. No sólo esto, sino que, además de traicionar su propio texto, se traiciona a sí mismo y a los lectores. Porque sobre el final, en “Pequeña Guía de Canciones Tristes (Un Juicio Final)”, declara: “Ahora aparezco y ¿quién soy yo? ¿El impostor que no muere? ¿El siempre dispuesto doble para las escenas de alto riesgo? ¿Alcanzará con decir que soy simplemente el narrador; que este libro no trata sobre mi persona oscureciendo los rostros de ciertos dramatis personae?” (258).

El texto (o los textos) se instala sobre una ecuación que la propia ideología textual quiere demostrar como falsa, aunque es incapaz de prescindir de ella: Dios es al mundo lo que el narrador es al texto. Aún más: Dios/narrador escribe el mundo/texto. ${ }^{6}$ Así pues, no hay límite entre realidad y ficción y por lo tanto, cualquier interpretación que se haga 
del primer binomio es aplicable al segundo. Sin embargo, esta propuesta lleva sobre sí los elementos de su propia traición: existe un narrador extradiegético que se deja tentar por lo absoluto, por la necesidad de estructurar su propia escritura y entregar al lector la clave (retrospectiva) de interpretación. Esta es la función de “(Una nota de agradecimiento \& algunas explicaciones más o menos pertinentes)”. Lo real se introduce en el espacio de la ficción para "explicar” aquello que el lector debe leer y desde donde debe hacerlo: “Una aclaración inicial: Este libro es un volumen de cuentos y no una novela y todos los cuentos de este libro empiezan y terminan más o menos igual y todos los cuentos de este libro cuentan más o menos la misma historia con la misma voz" (296). Lo que sigue es bibliografía: voces que autorizan la ficción y la hacen verosímil, pero esta vez, desde la ficción misma. El texto se vuelve contra sí mismo. Toda la operación textual consiste en espejarse, borrar límites, romper pactos de lectura (aún aquellos que sustentan la naturaleza misma de las operaciones textuales), citar infinita y asistemáticamente; la escritura opera sobre la única norma que permanece fiel al graffiti inicial: la inestabilidad. Esa inestabilidad borra las fronteras entre ficción y realidad, entre literatura e Historia (como veremos luego), pero no intenta crear espacios programáticos que apuntalen apuestas ideológicas y/ o políticas. El sema que recorre los textos es la precariedad de toda forma de ley, saber o verosimilitud y, por ende, la permanente tensión provocada por la coexistencia de entidades opuestas (y hasta excluyentes) en el mismo plano. La ficción se realiza donde es posible convocar contrarios que desestabilicen el nivel de la percepción y, con ello, posibles lecturas unívocas: "El verdadero y admirable logro de Stoker es ese trompe l'oeil sediento de sangre: una sombra dentro de otra sombra que — cuando ya es demasiado tarde para denunciarlo a las autoridades_ - sólo podemos describirla como lo que es: una sombra dentro de una sombra dentro de una sombra” (165).

Al ser inestables las figuras autorizantes del texto, no hay una narración, sino muchas. No hay una versión de los textos, sino muchas. Al ser todos los pactos traicionados, ${ }^{7}$ la estructura donde deberían apoyarse las entradas para la lectura tienden a disolverse. Al no haber fábula, la historia se reduce a un mero anecdotario: los textos son un espejismo de narración. En esta operación, Fresán instala su escritura dentro de la tradición experimental de los años setenta, sobre todo en la línea de Luis Gusmán o Néstor Sánchez, trayendo al centro del campo cultural operaciones límite, no sólo en un sentido estrictamente estético. Lo que se debate es la existencia de la literatura como artefacto.

El consumo literario, la cuestión de la lectura, de cómo se lee una novela que no es novela, una narrativa que no quiere escribir fábulas, permite acceder a la segunda parte de

\footnotetext{
${ }^{6}$ Esta incapacidad es el "agujero negro" del texto: es el lugar por donde todo circula para destrozarse. Aparentemente el texto es consciente de tal falencia y, en lugar de cubrirla, tiende más bien a reforzarla para fragmentar todo intento de aproximación, remitiendo a las operaciones textuales de los ensayos de Jorge Luis Borges, aunque sin su seguridad lúdica.

${ }^{7}$ Podría argüírse en contra de este planteo que hay textos donde se traicionan pactos de lectura o convenciones de género. Sin embargo, en estos casos, la estructura textual permanece mas allá de la traición, creando formas de lectura basadas en este hecho. Aquí, tales traiciones son llevadas a su último extremo: las traiciones se estafan a sí mismas, repitiendo el movimiento hasta el paroxismo y convirtiendo su naturaleza en un espejismo infinito que sólo desaparece con el final del relato.
} 
la operación textual. Desde las “señoritas”, los “miembros de la Fundación”, los "sacerdotes de la sociedad Bolandista” hasta "la familia” y las “autoridades del Vaticano”, los textos se niegan a identificarse con posibles modelos (ideológicos o no) de lectura. Todos los programas son congregados pluralmente porque el texto renuncia (al menos explícitamente) a ser portador de una ideología. Así como el narrador es una figura evanescente, los lectores no acaban de constituirse: toda interpretación es igualmente válida porque los relatos se niegan a definirse como tales.

Al no haber una armazón que sustente líneas de lectura desde la fábula, leer es una operación con la que se cuestionan los mecanismos de la escritura y la interpretación. Leer es un ejercicio de desentrañamiento y experimentación de lo que, en los textos, es percibido como a-histórico. La voluntad de la escritura es entorpecer la lectura, crearse a sí misma como un espacio de confrontación entre los diversos modos de ingresar a la ficción... y a la Historia y al campo cultural, todo en una misma operación:

Y viviremos hasta el día de nuestra muerte placenteramente atormentados por la búsqueda segura y el improbable descubrimiento de cuál es el mejor modo de contar una historia [...] La mala noticia es que la gran mayoría de los lectores parecen desear exactamente lo mismo; quieren que los ayudemos lo más posible, que mantengamos todo el asunto prolijo y limpio; quieren entender sin necesidad de esfuerzo alguno... (167)

De ahí que leer a otros en el texto conlleve los mismos términos que leer el propio texto. En el primer nivel (leer a otros), la cita se vuelve gratuita: genera interpretaciones que no conducen a ninguna parte dentro del relato. Es posible que esto sea más explícito en "El Espíritu Santo”. El texto está marcado por los destinatarios a quienes el narrador trata de iluminar y despistar a la vez: “escuchen”, “vean”, etc. Pero sobre todo genera un ámbito donde la ficción y lo real dejan de serlo para convertirse en un espacio ambiguo que revela lo artificioso de toda interpretación: "Lean conmigo: 'Exactamente encima de la yugular...'” (173) es a nivel de lo extradiegético lo que repite y anticipa la escena siguiente en el nivel intradiegético (el protagonista despierta con su propio cuello mordido) para parodizar la representación, la mise en abîme, pero sobre todo, el mecanismo de construcción del relato: no hay tal mordida, sino una broma pesada. A tal punto que lo textual se disuelve sobre sí mismo al ser atravesado de materiales extradiegéticos que desestabilizan los pactos de verosimilitud: "Antes que sea demasiado tarde me gustaría poder — tal como ya me ha sido solicitado por algunas asistentes a este curso- mostrarles una fotografía de El Freako" (175; el subrayado es mío). El texto deja de ser un simple relato, puesto que implota como tal en la carta del Freako, para convertirse en un mero recurso instrumental del aparato crítico: "lo que ahora se me vuelve a exigir como tiro de gracia es ni más ni menos que otro imposible: una nueva definición privada de la palabra literatura” (178). Y de manera aún más gráfica: "La literatura como el Freako; ese vampiro al que le abrimos la puerta para que nos cuente su historia con el implícito compromiso de volver a contarla algún día ...” (179). El texto se vuelve plenamente consciente de sí mismo, consciente de su independencia, y opera sobre esta certeza.

Darle al lector esta misma convicción para que opere de modo funcional dentro de los relatos es uno de los objetivos principales de los emisores. De ahí, justamente, la falta 
de estructura: sólo la lectura es capaz de otorgar sentido a la fábula. La fragmentación opera sobre la posibilidad de múltiples interpretaciones: los textos son como rompecabezas cuyas piezas tuvieran la maleabilidad suficiente como para acomodarse a cualquier exégesis. Así pues, no se propone un único lector ideal sino, más bien, una comunidad de lectores cuya participación en la organización textual tenga el mismo nivel que la de los narradores: la operación es simétrica a la ideología que sustenta la existencia de una comunidad virtual equitativa en Internet. Los textos (como la Red) se presentan como el espacio donde es posible realizar la pluralidad. El objeto de la narración ("contar historias”) cede paso al objeto de la lectura, es decir, la(s) interpretación(es), con lo cual el relato se explica a sí mismo al generar la posibilidad de sus propias lecturas. Pero, lo importante es que lo que actúa como disparador no es el texto mismo sino los materiales paratextuales que se incorporan: de ahí que la traición del pacto de lectura sea aún más violenta. Los textos se leen a sí mismos a través del aparato crítico que ponen en escena, y no solamente a través de sistemas (con)textuales.

No hay una libertad infinita de lecturas, sin embargo. En la propia traición del narrador en el capítulo final está la trampa donde las múltiples lecturas colapsan de la misma manera que los relatos: si hay una sola historia, y aparece una bibliografía, la pluralidad se constriñe a un único nivel, es decir, el nivel de Dios. Aun los blancos que los textos dejan no se producen al azar sino que son los vacíos de la falta de una estructuración adecuada. Los textos acaban debatiéndose entre lo dicho/ no dicho y las tensiones del lenguaje que no termina de abrirse paso a través de la ficción.

Si el sujeto (ya sea narrador, personaje o lector) se ha astillado hasta hacer imposible su recomposición, y el texto se ha convertido en un objeto que no tiene características pertinentes que lo definan como tal y, por ende, acaba fragmentándose. Aquello que conecta ambas partes de la ecuación, la historicidad, también se convierte en un puro espejismo: "los limpios relatos de mi juventud sólo me inspiran la más profunda de las desconfianzas" (69). Esta es, sin embargo, la mayor contradicción que presentan los relatos. Aun cuando la Historia sea en ellos un elemento evanescente, existe, permea las hipótesis textuales porque es la contracara de todos aquellos elementos que son leídos como a-históricos. Lo que se entiende como Historia no es la Historia misma sino los hechos más superficiales de la cotidianeidad y del consumo: el cine, la televisión, la música pop, las modas.

En los textos, la Historia (en tanto que continuidad) se ha convertido en parte integral de la subjetividad: no es ya un objeto concreto de la realidad externa, sino una virtualidad (igual que el propio texto) sujeta a múltiples interpretaciones de la subjetividad. Más aún, lo histórico existe sólo como parte de la subjetividad. En Vidas de santos, el tiempo es únicamente aquel cuya naturaleza permite el acceso individual de cada uno de los fragmentos en que se astillan sujetos y objetos, a una conciencia plural de la Historia como condición inherente a la conciencia. No por nada el primer parágrafo dice:

Este es el punto exacto donde comienza el final de todas las cosas. Todo se mueve en el más fluido de los presentes con alguna ligera insinuación de futuro. Por lo tanto, cualquier explicación de lo sucedido se vuelve innecesaria. El pasado es, apenas, un lenguaje que muy pocos reconocen y que sólo dominan con alguna mínima eficacia los más solipsistas académicos (9; énfasis mío). 
En la novela circular todos los puntos de vista posibles en un mismo plano de igualdad. Las voces de los asesinos y de sus víctimas, de los perseguidores y sus de presas cohabitan el mundo, enuncian, omiten, mienten, traicionan. No importa tanto lo que dicen, sino el hecho mismo de que digan. No hay juicio de valor sobre sus enunciados porque todos forman parte de la conciencia textual. Así como la voz del narrador no se desprende del proceso de construcción del relato, sino que antes bien, lo hace evidente, las múltiples conciencias que otorgan al relato su temporalidad tienden a mostrarse como las partes contradictorias (e integrales) de una conciencia múltiple. Para cada conciencia individual no hay más alternativa que la de su propio presente: "nada tiene sentido porque nada puede ser comprobado por Sebastián Coriolis” (39). Toda interacción (física) es violenta (como en el caso de las víctimas de Sebastián Coriolis) o fracasa (como en el caso de Alexo y Nina).

La ruptura de la linealidad histórica permite traer a la superficie la arbitrariedad de la interpretación, de la exégesis y el dogma a la hora de constituir relato. He aquí el signo de que este texto es uno de los primeros intentos de articular esta problemática como una sintomatología de los cambios que emergen en el campo cultural: la operación fracasa porque para poder realizar tal operación el texto debe traicionar sus propias apuestas, volverse paratextual y arrojar a los propios sujetos del relato a acciones hiperbólicas.

La subversión del tiempo histórico (y del espacio) desrealiza toda posible percepción mimética, aun las más limitadas. Pero no entra en el territorio de lo fantástico: no es una lectura que aspire al extrañamiento ni a lo maravilloso, sino que se constituye sobre la negación de la razón y de la lógica en el espacio perceptual de lo cotidiano. Es un horror que se regodea en sí mismo con satisfacción y que no quiere ser ajeno al sistema de percepción del lector. En los relatos, pasado, presente y futuro pertenecen a una misma categoría perceptual, donde las múltiples conciencias pueden circular a-temporalmente. Es en este preciso instante en que el texto crea una de sus mayores contradicciones: en su desesperado intento por desideologizarse, los narradores acaban aceptando el punto de vista del statu quo, integrándose a las normas a las cuales se resisten. Según esto, que "las historias son el modo en que creamos un orden" (12) y que "uno de los grandes placeres del artista reside en convertir lo inaceptable en creíble” (30), son las trampas del relato, las coartadas que el relato se construye para poder operar sobre sus propias y constantes contradicciones. Y es que, como observa Lyotard, "la representation hyperréaliste ne représente pas une première chose, mais seulement des items eux-mêmes déjà représentés...”. Dirá el narrador de "La Memoria de Todas las Cosas": "La historia ha sido contada y ahora sólo queda la resignada espera, el preguntarse — apenas — sobre cómo y cuándo reaccionará el destinatario de todo ésto, cómo recibirá el futuro inquilino [...] el santo espacio de este palacio de la memoria” (235). Se narra lo que ya ha sido narrado, pero confiriéndole un valor de verosimilitud por encima de su valor previo: la escritura y la lectura son un circuito de recirculación de materiales que son puestos bajo un lente deformante que permite desarraigarlos de toda contextualización. Lo que el texto hace es trabajar sobre el vaciado de sentido de la Historia, sobre la fragmentación de los conceptos de continuidad y devenir: el ser de los relatos es su arbitrariedad: “A veces — cada vez más seguido, a medida que se acerca el fin de todo lo que conocemos como real ...” (105). 
Siguiendo esta misma lógica, aquello que es el final de un modo de percibir el mundo es también un postulado de inicios. Si el texto renuncia a lo verosímil al abandonar relaciones causales, es sólo para establecer una nueva forma de conciencia histórica que trabaje desde lo fragmentario. Y sin embargo, para hacer esto, necesita operar desde el espacio absoluto, desde un tiempo a-histórico, convirtiendo cada instante de presente en un momento fundacional, tanto de las relaciones espacio- temporales, como de la escritura. Los textos de Vidas de santos se construyen sobre una visión apocalíptica del mundo. Y es justamente por eso, que los santos del texto operan como los jinetes bíblicos. Cada uno de los santos lleva una de las maldiciones de este fin de siglo: SIDA, Guerra Nuclear, Drogas, Violencia Cotidiana. Pero, a diferencia de los Jinetes del Apocalipsis, éstos se caracterizan por la gratuidad. No hay salvación posible. Después de su paso no quedará ni el Reino de los Cielos, porque Dios no existe. No habrá historia, ni ideología. Sólo habrá el infinito vacío de la nada. Con todo, los textos se resisten al nihilismo que ellos mismos proponen, y quedan flotando en un espacio de confusa alienación en la cual se regodean y que es la única salida a la cual se prende desesperadamente el narrador para parodiar final y arteramente sus propios fundamentos: "que estos cuentos fueran como barcos perdidos en la niebla de la espera de un faro salvador”.

En este sentido, Vidas de santos hace una apuesta que, aunque el texto no es capaz de sostener, se plantea como base de un proyecto escriturario que atraviesa el campo cultural argentino durante los ochenta. Ese proyecto aparece como una reflexión más profunda en Esperanto. Aquí se retoman las problemáticas que hemos analizado y se reconvierten los temas en vigor del campo cultural.

Esperanto (1997) es el cuarto libro y primera novela plena de Fresán. En el texto, se narra una semana en la vida de Federico Esperanto, famoso compositor de jingles publicitarios, único miembro sobreviviente de una legendaria banda de rock nacional, depresivo crónico que alterna sus visitas a su psicólogo (llamado Carlos Lombroso) con las visitas a su mujer (autorrecluída en un manicomio privado), a su madre y a su hermano, sin lograr entenderse o comunicarse con ninguno de ellos.

La novela se inicia en el domingo que constituye el último capítulo y regresa al lunes que inició la semana, para volver sobre los pasos de Esperanto en un recorrido circular donde el personaje se descubre a sí mismo y a su pasado. Pero, a la vez, la novela describe una Buenos Aires posmoderna donde los medios masivos de comunicación, las drogas, la corrupción, la fuerza del mercado, el psicoanálisis y el misticismo son las formas elegidas por los personajes para sobrevivir. Cada uno de los días de la semana es un capítulo donde el pasado y el presente se encadenan. De a poco, el lector va descubriendo la desgarradora historia personal de Esperanto: la desaparición y supuesta muerte de su primer amor y su hija, la muerte accidental de su propia hija años más tarde, el intento de suicidio de su mujer y sus arranques místicos posteriores; su conflictiva relación con su madre, su incapacidad para entenderse con su hermano. El único lazo afectivo sólido de Esperanto es su amigo, la Montaña García, su socio en la agencia de publicidad, quien es una especie de gigante obsesionado con su propia materia fecal y sus flatulencias. Interconectados por relaciones familiares y amistosas que no parecen sostenerse en nada sólido, los personajes circulan por Buenos Aires como las imágenes rápidas y inconexas de un videoclip, apenas sostenidas por la letra de la canción de la cual son telón de fondo (en este caso, las letras 
de los jingles y de las canciones de Esperanto). Las canciones escritas en claves sólo reconocibles por tribus musicales específicas apenas logran comunicar algo: el lenguaje es insuficiente y la percepción, incompleta.

No quisiéramos que la ironía del nombre Esperanto pasase desapercibida: el apellido tiene un doble sentido. Por un lado, se refiere al idioma artificial creado por Lazurus L. Zamenhof a fines del siglo xix para ser una herramienta diplomática y social. Por otro, apela, como es obvio, al imposible supuesto de la comunicación y el entendimiento universales, siempre presente en el subtexto de los medios masivos de comunicación y del mercado. Pero el lema de Esperanto es "Nadie me entiende”. Esperanto habla, pero no se comunica. Su sueño recurrente, obsesión sobre la que vuelve constantemente en sus sesiones con Lombroso, lo coloca en un escenario para cantar y, al intentarlo, descubre que tiene la boca llena de cosas: huesos viejos de pollo, pedacitos de madera, clavos, dientes sueltos... Atado a las dos grandes tragedias de su vida (la desaparición de Lisa y la muerte de su hija Albertina), Federico Esperanto está bloqueado y no puede escribir más canciones. Antes de eso, Esperanto era capaz de traducir en jingles publicitarios (cuando no en música de rock), los ritmos secretos del Universo, porque, “... le había explicado a la Montaña García que todo objeto, no importaba cual fuera, escondía una canción privada en la disposición de sus moléculas. Una melodía única y casi secreta a la que el objeto en cuestión se veía obligado a obedecer a ciegas, porque esa música íntima era la que lo definía ante los tímpanos de la Creación” (99).

Pero aún así, el lenguaje de Esperanto está limitado por la estética de la música de rock. Si por un lado le permitía conectarse con el mundo que lo rodeaba o con sus propias emociones, por el otro, le impedía relacionarse con lo real, con el "afuera” del mundo, fuera de los parámetros de su poética. Con su renuncia al "lenguaje universal de la música” (en palabras del licenciado Lombroso), el idioma de Esperanto se vuelve incomprensible. Pero no es sólo un problema de la relación con el lenguaje. También es un problema de las relaciones sujeto-objeto que aparecen mediatizadas por la estética (o su falta) de la televisión y la tecnología digital. Esperanto dice a su hermano:

\footnotetext{
Cuando yo era joven, la televisión era en blanco y negro y no costaba demasiado pensar que todo no podía pasar por ahí. Porque era una tosca imitación de la realidad. No buscaba suplantarla y te juro que hasta había propagandas con gente vieja que no tenía por qué limitarse a hacer nada más que de abuelos [...] ¿Sabés lo que pasa? Vos sos de la era del CD y yo soy de la era del LP. Vinilo. En mi tiempo todo tenía un LADO A y un LADO B. Como el Yin y el Yang. (62)
}

Ciertamente Esperanto tiene una visión crítica de esta situación. Las canciones de música de rock que en su infancia habían sido "himnos de batalla" de la rebelión y la renovación cultural, quedaban reducidas, por la fuerza de la lógica del mercado, a música de fondo para comerciales televisivos. Apenas con treinta y cinco años, Esperanto ya es viejo, anciano venerable y experimentado, frente a su hermano de veinte que lo mira como a un objeto de museo. Sentado eternamente frente al televisor, Dani/Tony habla con la sintaxis de los videoclips. Esperanto reflexiona: 
... le maravillaba que los jóvenes de hoy todavía estuvieran mínimamente capacitados para encarrilar el convoy de una oración con las palabras en el orden correcto. Artículo, sujeto y predicado. El motor del verbo. Nada complicado. Cosa fácil. Sencillo y limpio. El viejo sistema que permitía, al menos, la ilusión casi verosímil de que aún existía cierta ínfima comunicación entre los mortales. (44)

Es por eso que nadie entiende a Esperanto y que él no entiende a nadie. Esperanto ocupa un lugar de cruce, un espacio atravesado de todos los signos, pero vaciado de sentido. Esperanto ve el mundo en términos comparativos dados por la televisión, las nuevas tecnologías y el mercado: su casa familiar es como la de los locos Adams pero más lúgubre; sus canciones citan a Bob Dylan, su furia a Elvis Presley; su departamento es una irónica cita de los anuncios de discotecas; por su trabajo inexistente cobra los réditos de la agencia de publicidad que comparte con la Montaña García, etc. La historia personal de Esperanto no está inscrita en la Historia ni conectada con ella porque no constituye un capítulo previo a nada. Antes de su nacimiento sólo existen sus antepasados, cuyas fotografías cuelgan en los pasillos de su casa de Palermo: se pone en duda la existencia misma de quienes no están en las fotografías o aparecen en ellas medio borrosos.

A diferencia de Lisa y Roberto, sus compañeros en Cuentos Cortos (su famosa banda de rock), que se involucran en la guerrilla, para él la Historia se hace presente como chispazos, como flashes informativos, pequeños acontecimientos que lo afectan de modo discontinuo, aunque ciertamente brutal. No es simple desinterés o indiferencia: es la incapacidad para montarse a los sueños y pesadillas porque los fracasos de la Historia ya están inscritos en el entorno y deforman la percepción. Y Esperanto no es el único. De hecho, puede ser peor. Un ejemplo es Trasho quien

\begin{abstract}
— a pesar de su inmaculado aspecto de publicity-yuppie-, alguna vez había sido, no mucho tiempo atrás, el revulsivo líder de Muerte al Puto, una banda punk y fascistoide de relativo éxito en el ambiente underground de Buenos Aires. Trasho ahora formaba parte de la selecta y mercenaria brigada donde tanto fugitivos del rock como de la música de cámara le ponían la banda de sonido a una lata de tomates o a una espuma de afeitar. Ahora-cada vez con menor frecuencia-Trasho era un punk de fin de semana que consumía mejor cocaína y paraba todo, ofendido y escandalizado a la primera escupida del público sobre su campera de cuero Gucci. (87)
\end{abstract}

Así que Esperanto, como Trasho, es una figura en un no-lugar o, mejor aún, en un lugar invadido por tradiciones ajenas (frustrantes, derrotadas y, muchas veces, corruptas e inmorales, cuando no irracionales) contra las que es necesario rebelarse, y marcado por la obligación de inscribirse en la lógica del mercado para sobrevivir, sin ser plenamente ni viejo ni joven. Esperanto está atrapado. De un lado, sus padres son “una pareja de hippies profesionales recién expulsados del paraíso acuariano” (181). Del otro, Dani / Tony, un joven-viejo, a medias su hermano, a medias personaje de televisión, pero en definitiva, contundentemente, otro:

A nosotros no nos interesa sentirnos jóvenes. Somos jóvenes. El poder... complica. Hay que ejercer el poder. A nosotros lo único que nos interesa es que no nos hinchen las 
pelotas hasta el 1 de enero del año 2000, ¿entendés? Después sí: después la cosa cambia. Después llega nuestra Era, la Era de los Irrealistas Virtuales; y ahí sí que se les acaba la joda. ¿Sabés quiénes son los Irrealistas Virtuales? (171)

$\mathrm{Y}$ en un escenario que rodea a todos, en la atmósfera malsana del consumismo desenfrenado, los porteños circulan por Buenos Aires, convertidos en autómatas sujetos a la voluntad de los jingles de Cima Publicidad, la empresa de Esperanto y Montaña García, quien los describe como C.A.C.A. (Consumidor Anárquico y Compulsivo Argentino), y agrega que son:

La clase de bestia que sólo imagina a Shangri-La o a Xanadú como enormes e inabarcables shopping centers. Adictos irrecuperables a las bolsas y a los paquetes y al plástico de las tarjetas de crédito que suplantan así las leyes del tiempo y del espacio para flotar, felices, en la antimateria donde siempre hay algo más para consumir y ser consumido mientras se involuciona sin prisa y sin pausa alrededor de vidrieras dicroicas siempre encendidas. (80)

Aterrado, Esperanto los ve pasar desde los ventanales de los cafés, consciente de la imposibilidad de escapar, arrinconado, pero a sabiendas de que no se puede renunciar a eso sin renunciar a la sociedad:

\begin{abstract}
Esperanto los observó mintiéndose un desde afuera como esos peces de las profundidades que nunca se atreven a romper el margen de la superficie — ah, mira a toda la gente solitaria—, y comprendió el miedo de sentirse parte de ellos, eslabón en una cadena de parias en línea de montaje hacia la caja registradora y más allá de la tentación de cualquier carnada [...] Aquí estaban todos juntos pero todos solos. La distancia que los separaba era tan engañosa como la que separa, unas de otras, a las estrellas en el cielo: centímetros que en realidad son años luz. (152)
\end{abstract}

A medida que la semana avanza, Esperanto va revelándose ante sí mismo (y ante los lectores). Y en esas revelaciones Esperanto descubre que la realidad es irreal, virtual, un espacio ni objetivo ni subjetivo, sino más bien una telaraña de múltiples relaciones, a cuyo entramado sólo puede accederse en las revelaciones de la droga. Ya en casa de Lisa, convertida ahora en Marina Soldán, la esposa del militar que la secuestrara, Esperanto se descubre a sí mismo en un espejo y se sorprende. Y al comprender que nada es lo que realmente parece, siente que la vida es como "un televisor con serios problemas de sintonía, como un tubo catódico indisciplinado y desconcertante” (194).

Si algo entiende Esperanto es que la experiencia vital no puede ser comprendida como en un momento de inspiración, que no hay un aleph de la experiencia. Esperanto comprende que no comprende. O que su comprensión está limitada por la experiencia inmediata de la cotidianeidad. El pasado le es ajeno, así como sus deudas, aunque sea necesario pagarlas como propias. $\mathrm{Y}$ el presente resulta refractario a todo intento de reduccionismo: allí donde el peso de la Historia carece de sentido, nos dice la novela, el lenguaje hace implosión y sólo queda el arte. Si alguna duda cupiera, el texto termina con dos escenas. En la primera, Esperanto descubre la verdad sobre Lisa y su hija, se libera de 
su carga de culpabilidad gratuita e intenta (y quizás, logra) asesinar a Soldán, el extorturador de aquella. En la segunda, apenas una página, la discografía del músico aparece ampliada con un LP reciente, para coleccionistas, donde finalmente, liberado del peso de la Historia, Esperanto se comunica y canta.

A diferencia de Vidas de santos, Esperanto no intenta un pacto entre materiales ideológicos en abierto enfrentamiento. Aquí, la renuncia a la Historia se hace en función de salvar a la literatura para sí misma. No es que no haya Historia, sino que ésta es tangencial a las operaciones estéticas de la escritura y, por ende, es (o debería ser) ajena al sistema interno de circulación literaria. Quizá, nos dice Esperanto, en efecto la literatura sea un subproducto con respecto a los medios, como en algún momento de los ochenta decía Martín Caparrós. Pero, aunque así sea, igual es posible hacer de la literatura un arte de la comunicación: cuando Esperanto canta, en última instancia, hace poesía, es decir, Literatura.

En este sentido, la estética posmoderna presente en estas novelas permite que se desobedezcan los mandatos intelectuales del siglo xix. En esa operación, Fresán actúa en abierto enfrentamiento con la temática central para la producción del campo cultural. Al abrir su sistema de producción a zonas discursivas relacionadas con el consumo, el mercado, los medios masivos de comunicación y la música popular, sus textos establecen los parámetros de una nueva estética narrativa. La incorporación de nuevos materiales apuntala la aparición de temáticas que reorganizan el mapa del campo cultural argentino al cambiar sus temas en vigor: ya no hay que ser o actuar como la Generación del ’37. ¿Qué importa quiénes sean sus herederos? Lo que Esperanto entiende (y los santos no) es que, después de que todo lo sólido se desvanezca en el aire, la Literatura, metamorfoseada, transformada, otra, permanece.

\section{BiBLIOGRAFÍA}

Benzecry, Claudio E. "El almuerzo de los remeros. Profesionalismo y literatura en la década del '90”. Hispamérica 87 (Takoma Park, MD 2000): 17-30.

Cohen, Marcelo. El país de la dama eléctrica. Buenos Aires: Bruguera, 1984.

Fresán, Rodrigo. Vidas de santos. Buenos Aires: Ed. Planeta Biblioteca del Sur, 1993. Esperanto. Barcelona: Tusquets, 1997.

Jameson, Frederic. Postmodernism, or the Cultural Logic of Late Capitalism. Durham: Duke University Press, 1993.

Lyotard, Jean-François. Dispositifs pulsionnels. Paris: Christian Burgois Editeur, 1979. Palaversich, Diana. "Rebeldes sin causa. Realismo mágico vs. realismo virtual". Hispamérica 86 (Takoma Park, MD 2000): 55-70.

Plotnik, Viviana P. "Mitos de la nación y posmodernidad en Historia Argentina de Rodrigo Fresán”. Hispamérica 87 (Takoma Park, MD 2000): 127-35.

Sarlo, Beatriz. Escenas de la vida posmoderna. Intelectuales, arte y videocultura en la Argentina. Buenos Aires: Ariel, 1994. 